BASINDO : Jurnal Kajian Bahasa, Sastra Indonesia, dan Pembelajarannya

Volume 3 Nomor 1, 2019

Journal homepage : http://journal2.um.ac.id/index.php/basindo

\title{
PENGEMBANGAN BUKU ELEKTRONIK BERTEMA KEBERAGAMAN PANGAN POKOK UNTUK MENDUKUNG GERAKAN LITERASI DI SMA-SMK
}

\author{
Ari Ambarwati ${ }^{*}$ \\ PBSI-FKIP Universitas Islam Malang (UNISMA) Jl. MT Haryono 193 Malang
}

\begin{tabular}{|c|c|}
\hline A R T I C LE I N F O & A B S T RACT \\
\hline $\begin{array}{l}\text { Article history: } \\
\text { Received: } 16 \text { May } 2019 \\
\text { Accepted: } 23 \text { May } 2019 \\
\text { Published: } 31 \text { May } 2019 \\
\text { Keyword: } \\
\text { keberagaman pangan pokok, } \\
\text { buku pengayaan elektronik }\end{array}$ & $\begin{array}{l}\text { Pengakuan atas keragaman pangan pokok adalah upaya } \\
\text { menghargai perbedaan laku budaya konsumsi pangan pokok } \\
\text { masyarakat Indonesia. Tujuan penelitian ini adalah menyusun buku } \\
\text { pengayaan bertema keberagaman makanan pokok } \\
\text { Indonesia.Metode yang digunakan dalam penelitian adalah } \\
\text { penelitian pengembangan (Research and Develompment). Penelitian } \\
\text { dan pengembangan yang dilakukan mencakup tiga tahap, yaitu } \\
\text { pengumpulan informasi, perencanaan, dan pengembangan draf } \\
\text { produk.Hasil penelitian berupa model buku pengayaan elektronik } \\
\text { dengan konten sejarah, kandungan gizi, narasi, dan serba-serbi } \\
\text { tentang jagung, singkong, sagu, pisang, dan padi. Hasil validasi ahli } \\
\text { materi memberi presentase skor } 84 \% \text {, ahli media memberi } \\
\text { presentase } 83 \% \text {, dan ahli grafika memberi presentase skor } 86 \% \text {. } \\
\text { Hasil itu menunjukkan bahwa buku pengayaan elektronik ini layak } \\
\text { digunakan. }\end{array}$ \\
\hline
\end{tabular}

Recognition of the staple food diversity is an effort to respect the differences of cultural conduct on consuming staple food in Indonesia. The purpose of the study is composing the electronic enrichment book themed on the Indonesian staple food diversity. The research method used is research and development. Research and development performed in three phases, namely, information gathering, planning, and development of product draft. Research result is the model of the electronic enrichment book contains about history, nutrient content, narration, and interesting facts on maize, tubers, sago palms, bananas, and rice. The results of validation experts give a percentage score $84 \%$ for material, media expert give percentage of $83 \%$, and the graphics give a percentage score of $86 \%$. The results show that the electronic enrichment book is feasible to use.

\footnotetext{
* Corresponding author.

E-mail addresses: ariati@,unisma.ac.id (Ari Ambarwati)
}

ISSN : 2579-3799 (Online) - BASINDO : Jurnal Kajian Bahasa, Sastra Indonesia, dan Pembelajarannya is licensed under Creative Commons Attribution-ShareAlike 4.0 International License (http://creativecommons.org/licenses/BY/4.0/). 
Makanan pokok merupakan makanan utama yang dikonsumsi suatu masyarakat. Ada 77 bahan tanaman berkabohidrat yang diolah dan dikonsumsi sebagai makanan pokok dan tersebar di seluruh wilayah Indonesia (Kompas, 2018). Faktanya, dari 77 tanaman berkabohidrat yang dapat dijadikan makanan pokok, masyarakat Indonesia mengenal beberapa saja, diantaranya adalah beras, jagung, umbi-umbian, sagu, sorgum, dan pisang. Realitas itu menunjukkan bahwa potensi bahan pangan yang ada di wilayah Indonesia belum dimanfaatkan secara maksimal. Nusantaranews (2016) menyatakan bahwa kebijakan pangan pemerintah masih bertumpu pada beras, sebagai pangan pokok utama. Konsumsi masyarakat Indonesia pada beras juga tinggi, yaitu $133,26 \mathrm{~kg}$ pertahun.

Paparan tersebut menjelaskan bahwa potensi bahan pangan belum dikelola dengan baik. Pangan pokok di luar beras masih menjadi anak tiri yang belum dimanfaatkan dengan maksimal sebagai komoditas pangan rakyat untuk memenuhi kondisi tahan pangan, apalagi daulat pangan (Ambarwati, 2019: 2). Pengistimewaan beras sebagai pangan pokok menjadi kontraproduktif dalam perspektif kebinekaan Indonesia. Indonesia beragam, termasuk dalam hal pangan pokok yang sudah dikonsumsi masyarakat Indonesia secara turun-temurun. Nasionalisasi beras yang dilakukan pemerintah pada tahun 1960 an mengakibatkan ketergantungan masyarakat Indonesia pada beras meninggi (Rahman, 2016:267). Realitas ini meminggirkan komoditas pangan pokok nonberas, sehingga proses kastanisasi pangan pokok di Indonesia terbentuk secara politis.

Pengakuan keberagaman pangan pokok yang dikonsumsi masyarakat Indonesia adalah langkah strategis yang dapat dilakukan untuk mencapai kondisi ketahanan sekaligus kedaulatan pangan. Langkah itu dapat diupayakan melalui penyusunan buku pengayaan elektronik yang memuat tema keberagaman pangan pokok masyarakat Indonesia.

Buku pengayaan merupakan buku bacaan yang ditulis untuk memperkaya pengetahuan, perspektif, wawasan, serta informasi pembacanya (Permendiknas No 2, 2008). Buku pengayaan elektronik berarti buku pengayaan yang disusun melalui program tertentu di komputer yang mampu menghadirkan visualisasi hidup, tidak hanya berisi teks tulis, tetapi juga suara dan gambar bergerak. Buku pengayaan merupakan bahan bacaan yang bisa dipajankan untuk Gerakan Literasi Sekolah (GLS). GLS adalah upaya dan kegiatan partisipatif aktif yang melibatkan warga sekolah, masyarakat umum dan pemangku kebijakan di bawah koordinasi Direktorat Jenderal Pendidikan Dasar dan Menengah Kementerian Pendidikan dan Kebudayaan Republik Indonesia (Dirjendikdasmen Kemdikbud RI) (Dirjendikdasmen Kemdikbud, 2016: ii). GLS ditandai dengan rutinitas membaca selama 15 menit sebelum memulai pelajaran. Sejak diluncurkan pada 2016, GLS sudah dilaksanakan di tingkat SD, SMP-MTs, hingga SMA-SMK-MA.

Buku pengayaan elektronik bertema keragaman makanan pokok Indonesia penting untuk disusun dengan pertimbangan bahwa buku itu dapat digunakan sebagai sumber pengetahuan yang memperkaya pengetahuan dan informasi tentang keanekaragaman bahan makanan pokok masyarakat Indonesia. Buku tersebut juga memperkaya pengalaman pembaca terhadap sejarah kehadiran, narasi, serta bagaimana pangan pokok tersebut membentuk budaya masyarakat pengonsumsinya, dengan tampilan yang lebih atraktif dibandingkan buku cetak.

Berdasarkan analisis kebutuhan awal, didapatkan informasi bahwa (1) pembaca usia 16 tahun ke atas menyukai buku berbentuk elektronik, (2) sebagian besar pembaca menyukai teks yang tidak terlalu panjang (antara 2000 - 4000 kata tiap judul bacaan), (3) pembaca menyukai desain sampul buku yang berwarna, (4) Pembaca menyukai aneka jenis teks yang berbeda dalam satu bab, (5) pembaca lebih suka teks dituliskan dalam ragam bahasa campuran (formal dan nonformal), (6) pembaca menyukai adanya ilustrasi, gambar, gambar bergerak, animasi, suara, dan infografik di tiap halaman buku.

Penelitian sejenis yang pernah dilakukan adalah tentang Pengembangan Media Pembelajaran Visualisasi Nilai-nilai Pancasila Berbasis Teknologi Informasi dan Komunikasi (Buchory dkk, 2017). Penelitian itu mengembangkan media pembelajaran menggunakan macromedia flash untuk memajankan nilai-nilai Pancasila pada siswa Kelas V. Penelitian sejenis berikutnya adalah Pengembangan Ebook. Memahami Cara Menulis Cerkak Bahasa Jawa Dengan Menggunakan Sumber Ide 
Gambar Berseri untuk. Siswa Kelas XII yang dilakukan oleh Annisya dan Suyitno (2018). Penelitian itu mengembangkan buku elektronik menulis cerita pendek untuk siswa kelas XII. Dua penelitian tersebut mengembangkan buku elektronik untuk matapelajaran Pendidikan Kewarganegaraan dan Bahasa Jawa. Kedua penelitian itu mengembangkan buku elektronik, tetapi tidak berfokus pada buku pengayaan yang bertema keberagaman pangan pokok Indonesia.

Berdasarkan urgensi penelitian tentang buku pengayaan bertema keberagaman makanan pokok masyarakat Indonesia, analisis kebutuhan awal tentang buku pengayaan elektronik, dan realitas penelitian sejenis, maka dilakukan penelitian Pengembangan Buku Elektronik Bertema Keberagaman Pangan Pokok untuk. Mendukung Gerakan Literasi Di SMA-SMK. Tujuan penelitian ini adalah menyusun buku pengayaan berbentuk buku elektronik sesuai dengan perjenjangan buku, yang berisi tentang keberagaman makanan pokok masyarakat Indonesia.

\section{METODE}

Penelitian ini memakai rancangan penelitian dan pengembangan (research and development) untuk menyusun buku pengayaan elektronik bertema keberagaman makanan pokok masyarakat Indonesia. Metode penelitian dan pengembangan merupakan metode yang dilaksanakan untuk menghasilkan produk khusus dan menguji keefektifan produk yang dihasilkan.

Penerapan pengembangan buku ini mengadopsi tahapan penelitian dan pengembangan. Penerapan penelitian dan pengembangan dilakukan sampai langkah keempat. Langkah pertama adalah mengidentifikasi potensi dan masalah buku pengayaan elektronik sesuai perjenjangan buku dengan konten keberagaman makanan pokok masyarakat Indonesia, mengumpulkan data terkait, mendesain model buku pengayaan elektronik, dan memvalidasi desain buku kepada ahli materi, ahli media, dan praktisi (pembaca). Langkah penelitian pengembangan pada penelitian ini dapat digambarkan sebagai berikut.

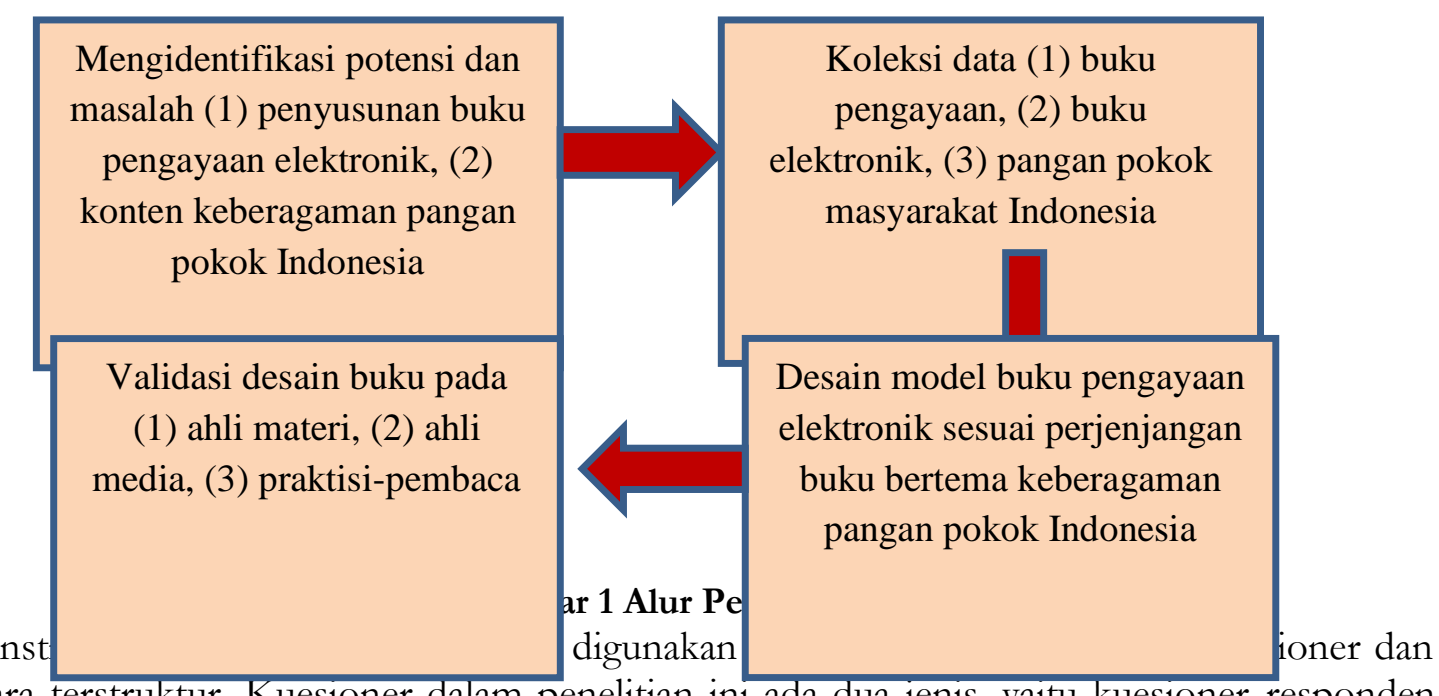

wawancara terstruktur. Kuesioner dalam penelitian inı ada dua jenis, yaitu kuesioner responden dan kuesioner validator. Kuesioner untuk responden ada dua macam yaitu kuesioner desain buku dan kuesioner konten buku. Kuesioner untuk responden dilaksanakan untuk mengetahui kebutuhan dan preferensi mereka terhadap buku pengayaan elektronik. Sedangkan kuesioner untuk ahli media, ahli materi, dan pembaca dilakukan untuk mengukur tingkat keterbacaan buku melalui pemilihan materi yang sesuai, ketepatan konten, dan desain buku sesuai perjenjangan buku tingkat $\mathrm{F}$ untuk membaca mahir. Wawancara terstruktur dilakukan untuk menggali informasi lebih detil tentang kebutuhan dan preferensi desain dan konten buku pengayaan elektronik.

Teknik analisis data yang digunakan dalam penelitian ini adalah teknik analisis data kuantitatif dan kualitatif. Teknik analisis data kuantitatif dilakukan pada hasil kuesioner ahli materi, ahli desain, pembaca, dan kuesioner responden yang berupa prosentase kebutuhan dan 
preferensi. Sementara teknik analisis data kualitatif digunakan untuk mengolah data verbal dan tertulis yang berupa jawaban dan komentar responden, saran, dan masukan dari informasi dari ahli.

\section{HASIL}

Hasil penelitian dan pengembangan berupa Pengembangan Buku Elektronik Bertema Keberagaman Pangan Pokok Untuk Mendukung Gerakan Literasi Di SMA-SMK.

Pemaparan hasil menguraikan deskripsi produk buku dan hasil validasi ahli.

\section{Deskripsi Produk}

Produk penelitian ini ialah Buku Pengayaan Elektronik Bertema Keberagaman Pangan Pokok Indonesia. Buku pengayaan elektronik ini dibuat berdasarkan prinsip perjenjangan buku nonteks pelajaran. Buku ini ditujukan untuk siswa kelas X ke atas dan masyarakat umum. Perjenjangan buku pengayaan ini di tingkat $\mathrm{F}$ untuk membaca mahir. Produk buku pengayaan sesuai perjenjangan buku bertema keberagaman makanan pokok masyarakat Indonesia ini memuat tiga aspek yaitu (a) Isi, (b) Bahasa, dan (c) Grafika.

Aspek isi dalam buku pengayaan memiliki komponen teks nonfiksi dan fiksi. Teks nonfiksi berupa paparan sejarah, informasi, pengatahuan, olahan makanan pokok, dan fakta kandungan gizi makanan pokok. Teks fiksi berbentuk cerita rakyat yang mengisahkan makanan pokok, syair atau nyanyian tentang makanan pokok.

Aspek bahasa dalam buku pengayaan berupa pemakaian bahasa formal dan nonformal, kosakata arkaik, teknis, sastrawi, serta figuratif. Tiap bab dalam buku pengayaan dimulai dengan kalimat pemantik untuk pembaca dan diakhiri dengan trivia berupa kumpulan informasi ringan terkait makanan pokok. Ada lebih dari satu jenis teks dalam tiap bab. Judul buku pengayaan ini adalah Nusantara dalam Piringku: Merayakan Keberagaman Makanan Pokok.

Aspek grafika dalam buku pengayaan ditandai dengan penggunaan huruf berkait (serif) dan tidak berkait (sans serif), dengan ukuran huruf 11. Spasi 1,5 dan huruf hitam atau berwarna. Gambar, infografik, dan video disesuaikan dengan materi. Gambar sampul depan dan belakang menyesuaikan dengan warna buku nonteks pelajaran jenjang $F$ yaitu nila berikut aneka gradasinya.Gambar sampul menunjukkan ilustrasi lima makanan pokok yang ditulis dalam buku yakni jagung, umbi-umbian, sagu, pisang, dan padi.

Produk buku pengayaan elektronik ini juga mempertimbangkan hasil analisis kebutuhan awal responden.

\section{Preferensi Buku Pengayaan Elektronik \\ (Dalam Prosentase; 60:40)}

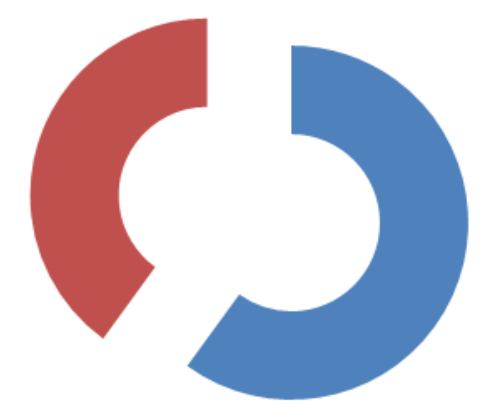

- Suka

- Cukup suka

-

-

Gambar 2 Preferensi Buku $60 \%$ responden menyukai buku pengayaan elektronik, sedangkan $40 \%$ cukup menyukainya. 


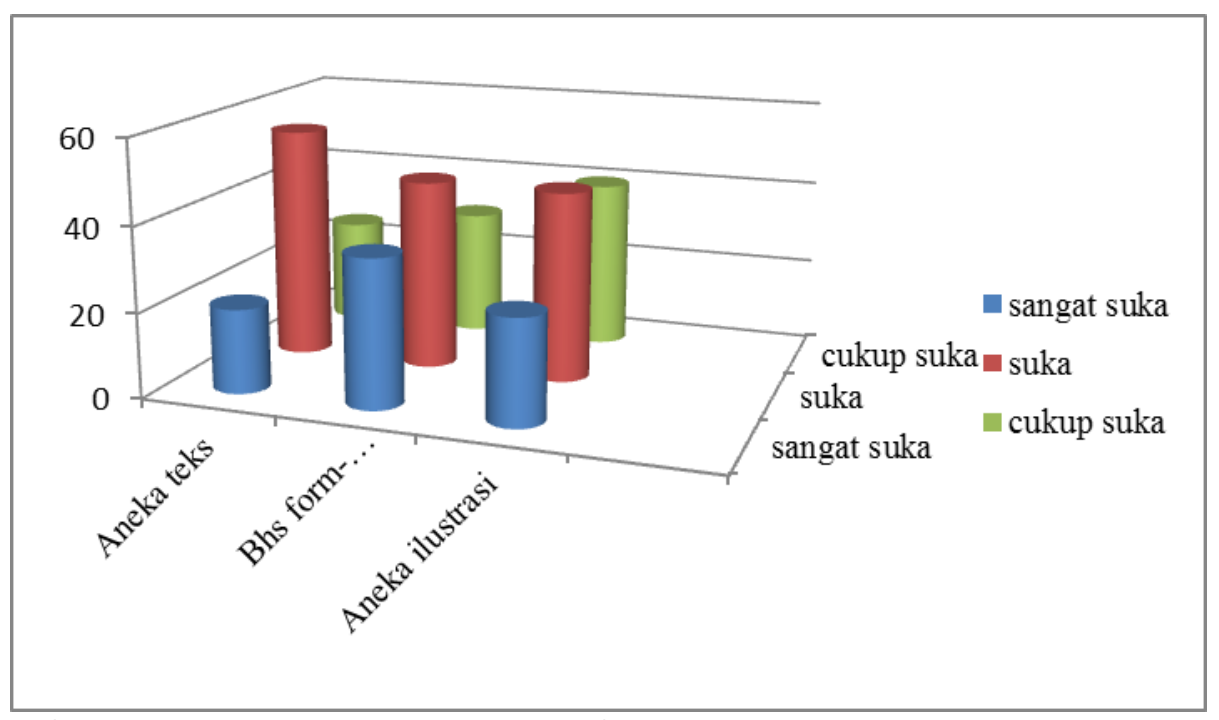

Gambar 3 Preferensi Isi, Bahasa\&Grafika Buku Pengayaan Elektronik

Gambar di atas menunjukkan bahwa dari aspek isi, jenis teks yang beragam dalam buku, bahkan dalam satu bab disukai pembaca. Dari aspek bahasa, responden menyukai ragam bahasa campuran dalam buku pengayaan elektronik, yaitu bahasa formal dan nonformal. Dalam aspek grafika buku pengayaan elektronik, responden menyukai berbagai jenis ilustrasi buku, mulai gambar, gambar bergerak, hingga informasi yang dihadirkan dalam bentuk gambar berupa infografik. Semua responden menyukai buku pengayaan elektronik. Preferensi dan kebutuhan responden terhadap isi buku pengayaan elektronik mencapai angka 55\%, sedangkan kesukaan dan kebutuhan atas bahasa dan grafika adalah $45 \%$.

\section{Hasil Validasi Ahli}

Hasil produk penelitian dan pengembangan ini divalidasi atau diuji oleh tiga ahli. Tiga ahli itu adalah ahli materi, ahli media, dan pembaca yang merupakan seorang jurnalis. Ahli materi dan ahli media dipilih berdasarkan kriteria (1) memiliki pendidikan berlatar belakang Pendidikan Bahasa dan Sastra Indonesia, dengan pendidikan Doktor, (2) Bidang ahli yang dikuasai adalah menulis kreatif, ahli bahasa, perjenjangan buku dengan berbagai jenis teks untuk ahli materi buku, dan media buku pengayaan elektronik sesuai perjenjangan buku bertema keberagaman makanan pokok masyarakat Indonesia, (3) masa kerja ahli di bidang yang ditekuni minimal delapan tahun. Pembaca yang memvalidasi produk buku pengayaan elektronik adalah jurnalis di media nasional. Kriteria yang ditetapkan untuk menentukan praktisi pembaca adalah (1) memiliki latar belakang pendidikan minimal sarjana yang memahami bacaan dan tulisan dalam bahasa Indonesia, (2) memiliki pengalaman menulis dengan bahasa Indonesia minimal 10 tahun, (3) memiliki kecakapan menilai dan mengevaluasi bahan bacaan. Kajian para ahli pada produk buku pengayaan elektronik ini meliputi tiga komponen, yaitu (1) komponen isi, (2) bahasa, dan (3) grafika.

Komponen isi divalidasi oleh ahli materi, ahli media, dan praktisi pembaca. Ahli materi memberi skor $84 \%$ yang berarti baik dan layak sehingga bisa diterapkan. Ahli materi memberi catatan (1) urutan materi penyajian tiap bab dibuat sama, mulai dari sejarah masuknya pangan pokok ke Indonesia, informasi dan pengetahuan, narasi, dan trivia di penutup bab dan (2) kata beras di bab 1 diganti dengan padi dan ditukar posisinya dengan jagung di bab 5. Ahli media memberikan skor $83 \%$ pada komponen isi buku pengayaan elektronik. Ahli media memberikan masukan agar warna buku disesuaikan dengan perjenjangan buku. Mengingat buku ini ditargetkan untuk pembaca tingkat mahir, maka warna sampul dan warna buku yang dominan adalah nila. Pembaca yang berprofesi jurnalis memberikan skor $86 \%$ pada komponen isi buku pengayaan elektronik. Pembaca memberikan saran agar tidak terlalu banyak menggunakan warna dalam satu halaman, karena akan memecah konsentrasi. Judul buku agar dibuat menjadi lebih konkrit dan operasional. 
Hasil validasi bahasa oleh ahli materi ialah $83 \%$ yang berarti baik dan layak untuk didesiminasikan. Masukan untuk komponen bahasa adalah konsistensi penggunaan ragam bahasa formal untuk materi sejarah masuknya makanan pokok ke Indonesia. Ahli media memberikan skor $85 \%$ untuk komponen bahasa dalam buku pengayaan elektronik. Ahli media memberikan saran agar menggunakan dua macam bentuk huruf saja dalam tiap halaman, supaya keterbacaannya maksimal. Sedangkan praktisi memberi skor $88 \%$ pada komponen bahasa buku pengayaan elektronik. Praktisi menyarankan untuk membuat glosarium untuk menjelaskan katakata arkaik, kosakata berbahasa daerah, dan kata-kata teknis atau kata-kata serapan baru agar pembaca lebih memahami bacaan.

Hasil validasi grafika oleh ahli materi adalah $87 \%$ yang berarti sangat layak dan sangat bagus untuk diterapkan. Ahli materi tidak memberikan saran dan komentar terhadap komponen grafika. Ahli media memberikan skor 85\% untuk komponen grafika. Ahli media memberikan masukan agar dalam ukuran huruf dalam infografik dibuat lebih besar, supaya terbaca dengan jelas. Pembaca memberikan skor $87 \%$ pada komponen grafika dalam buku pengayaan elektronik. Pembaca memberikan masukan supaya infografik ditampilkan tidak hanya secara horizontal, tetapi juga vertikal.

\section{PEMBAHASAN}

Dari hasil penelitian dapat dinyatakan bahwa buku elektronik disukai oleh pembaca. Dari 27 responden yang diberi kuesioner, semua menyatakan suka dengan buku elektronik. Buku elektronik (e-book) merupakan versi elektronik dari buku cetak yang bisa dibaca di komputer atau perangkat elektronik genggam lain (kamus Oxford, 2018). Buku elektronik merupakan buku yang dapat diakses dan dibaca secara digital yang berisi teks, gambar, suara, dan gambar bergerak (video).

Awalnya buku pengayaan elektronik sesuai perjenjangan buku bertema keberagaman pangan pokok yang dibuat dengan dominasi warna hijau, dengan alasan untuk merepresentasikan kesuburan alam Indonesia. Tetapi ahli media mengingatkan bahwa buku pengayaan elektronik ini disusun sesuai dengan perjenjangan buku yang ditandai dengan perbedaan warna. Buku pengayaan elektronik ini ditujukan untuk pembaca mahir (jenjang F), maka warna yang dominan mulai dari sampul dan isi adalah warna nila dengan berbagai gradasinya. Sementara warna hijau ditujukan untuk buku nonteks pelajaran dan buku pengayaan jenjang D (membaca lancar) (Puskurbuk, 2018:15). Perjejanjangan buku nonteks pelajaran yang dibuat oleh Pusat Kurikulum dan Perbukuan Kementerian Pendidikan dan Kebudayaan dapat dicermati seperti berikut.

Tabel 1 Perjenjangan Buku Nonteks Pelajaran Puskurbuk

\begin{tabular}{|l|l|l|l|}
\hline No & Jenjang & Warna & Sasaran \\
\hline 1 & A & Merah & Pra-Membaca \\
\hline 2 & B & Jingga & Membaca Dini \\
\hline 3 & C & Kuning & Membaca Awal \\
\hline 4 & D & Hijau & Membaca Lancar \\
\hline 5 & E & Biru & Membaca Lanjut \\
\hline 6 & F & Nila & Membaca Mahir \\
\hline 7 & G & Ungu & Membaca Kritis \\
\hline
\end{tabular}

Tabel 1 dituliskan sesuai dengan naskah perjenjangan buku nonteks pelajaran yang dibuat oleh Puskurbuk. Warna sampul dan isi buku pengayaan elektronik berbasis keberagaman makanan pokok Indonesia yang awalnya berwarna biru, diubah menjadi nila. 


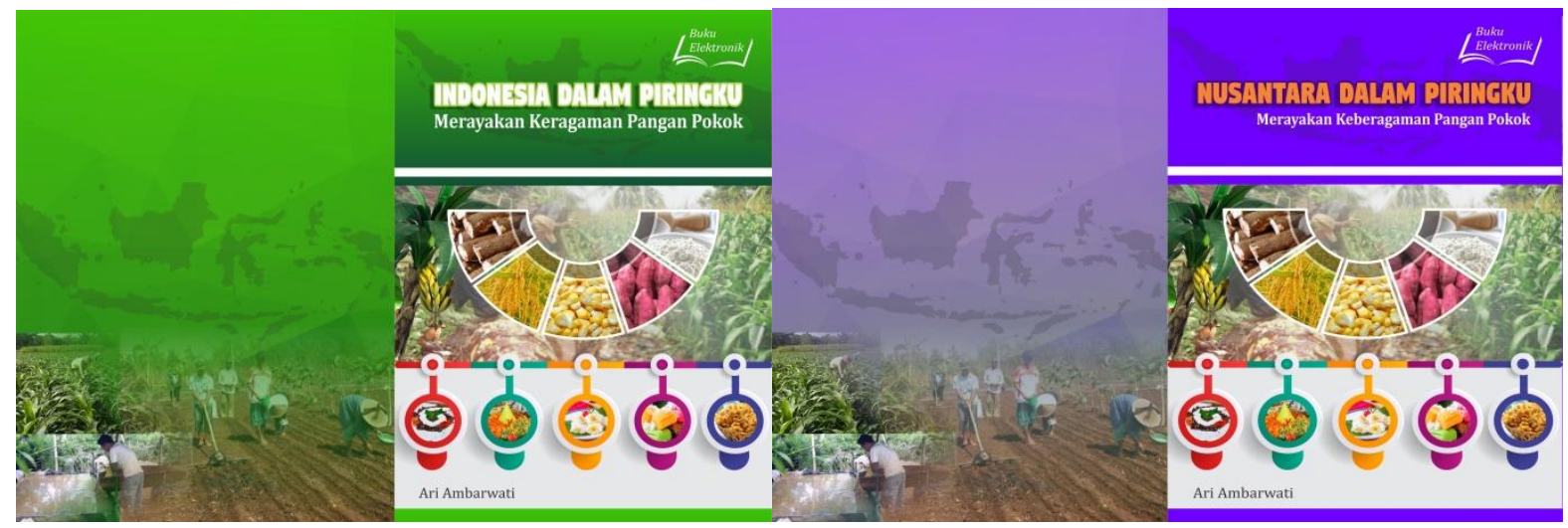

Gambar 4 Desain Sampul dan Warna Buku Pengayaan Elektronik

Buku pengayaan elektronik dibuat dengan mempertimbangkan analisis kebutuhan buku elektronik dengan menyebarkan kuesioner dan wawancara terstruktur pada responden. Analisis kebutuhan ini dibuat untuk mengetahui dan memetakan preferensi dan kebutuhan pembaca terhadap buku bacaan elektronik. Analisis kebutuhan juga dibuat untuk memberikan informasi awal purwarupa buku bacaan elektronik yang disukai dan dibutuhkan pembaca. Analisis kebutuhan digunakan sebagai alat untuk mengidentifikasi masalah guna menentukan tindakan yang tepat (Wahyuni, 2014:131). Tindakan yang tepat dalam penelitian ini adalah mengumpulkan bahan materi dan desain yang sesuai preferensi responden untuk menyusun buku pengayaan elektronik bertema keberagaman makanan pokok Indonesia.

Selain mempertimbangkan hasil analisis kebutuhan pembaca, penelitian ini juga menggunakan perjenjangan buku sebagai acuan untuk menyusun buku pengayaan elektronik. Buku pengayaan berperan sebagai suplemen buku pelajaran. Buku pengayaan merupakan buku pendukung pembelajaran, berfungsi sebagai pendamping buku teks, yang berujuan memperkaya pengetahuan dan cara pandang, membentuk kepribadian, dan sebagai sarana meningkatkan keterampilan peserta didik.

Ada tiga aspek dalam perjenjangan buku yang perlu diperhatikan. Tiga aspek tersebut adalah isi, bahasa, dan grafika. Aspek isi yang dimunculkan dalam buku pengayaan elektronik ini adalah penggunaan komponen teks fiksi dan nonfiksi. Teks nonfiksi dan fiksi ditampilkan dalam buku pengayaan elektronik sesuai dengan naskah akademik perjenjangan buku tingkat $\mathrm{F}$ untuk membaca mahir. Unsur nonfiksi yang ditampilkan dalam buku pengayaan elektronik ini berupa sejarah, fakta, data, isu pangan pokok masa depan, masalah sosial, dan budaya terkait pangan pokok.Unsur nonfiksi yang ditawarkan berbentuk cerita rakyat tentang asal mula jagung, sagu, dan padi, lagu tentang makanan bertanam jagung, dan mitos tentang singkong.

Aspek bahasa yang dimuat dalam buku pengayaan elektronik ini berbentuk penggunaan ragam bahasa formal dan nonformal dalam teks nonfiksi dan fiksi, gaya bahasa figuratif, arkaik, dan sastrawi dalam teks cerita rakyat, Penggunaan ragam bahasa formal dan nonformal merupakan preferensi dan kebutuhan yang diperoleh dari kuesioner responden. Paduan ragam bahasa formal dan nonformal dalam buku bacaan membuat responden lebih suka membaca. Jenis teks yang beragam, mulai dari teks deskripsi, eksposisi, teks, narasi, hingga teks prosedural yang dimasukkan dalam buku pengayaan elektronik ini, memungkinkan pembaca tertantang untuk membaca. Shananan, dkk (2012) dan Cardullo (2017) menyatakan bahwa teks yang menantang untuk dibaca adalah teks yang dibingkai secara kompleks, yang meliputi pengetahuan kata, struktur kalimat dan koherensi, organisasi penulisan serta pengetahuan latar belakang materi.

Saat penyusunan awal, buku ini diberi judul Indonesia dalam Piringku. Sejalan dengan studi pustaka yang dilakukan peneliti, diketahui bahwa wilayah persebaran lima pangan pokok (jagung, singkong, sagu, pisang, dan padi) tidak hanya sebatas Indonesia yang merujuk pada wilayah administratif Negara, tetapi juga wilayah yang lebih luas, yaitu Nusantara. Realitas itu memberi landasan untuk mengubah judul buku pengayaan elektronik ini. Nusantara memberi perspektif 
ideologis tentang wilayah kepulauan yang lebih luas dan digunakan sebagai sinonim untuk kepulauan Indonesia.

Jenis teks yang beragam, ragam bahasa formal dan nonformal, organisasi penulisan yang kompleks, serta pengetahuan latar belakang materi merupakan unsur yang membangun teks kompleks yang menantang pembaca. Kompleksitas teks dalam buku pengayaan elektronik ini juga ditunjang oleh keunggulan elektronis yang memungkinkan pembaca mendengarkan suara dan menyimak video tentang materi pangan pokok. Teks yang ditampilkan tidak saja teks yang tertulis, tetapi juga teks audio dan teks audiovisual. Buku elektronik menuntut para pembaca tidak hanya memiliki keterampilan membaca layaknya saat membaca buku konvensional (cetak), tetapi mereka harus mengembangkan kemahiran membaca dan menyimak untuk memahami teks yang multimodal. Teks multimodal dalam buku pengayaan elektronik dapat dilihat berikut ini.

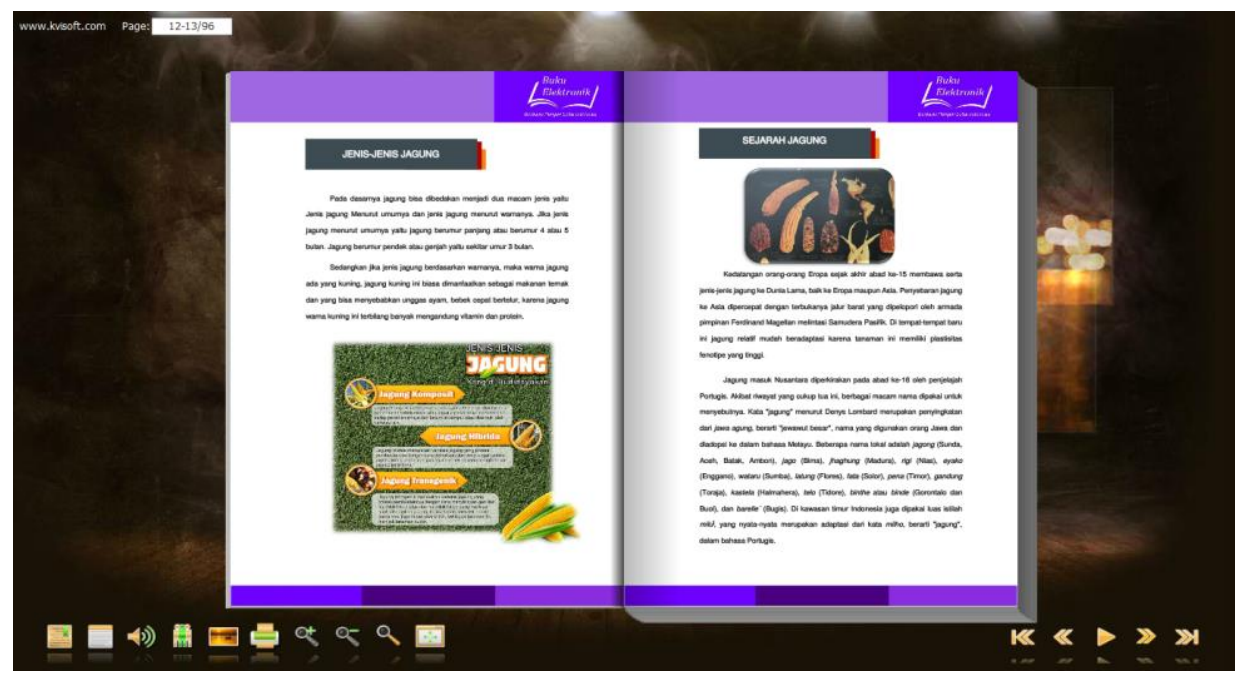

Gambar 5 Teks, Infografik, dan Gambar tentang Jagung

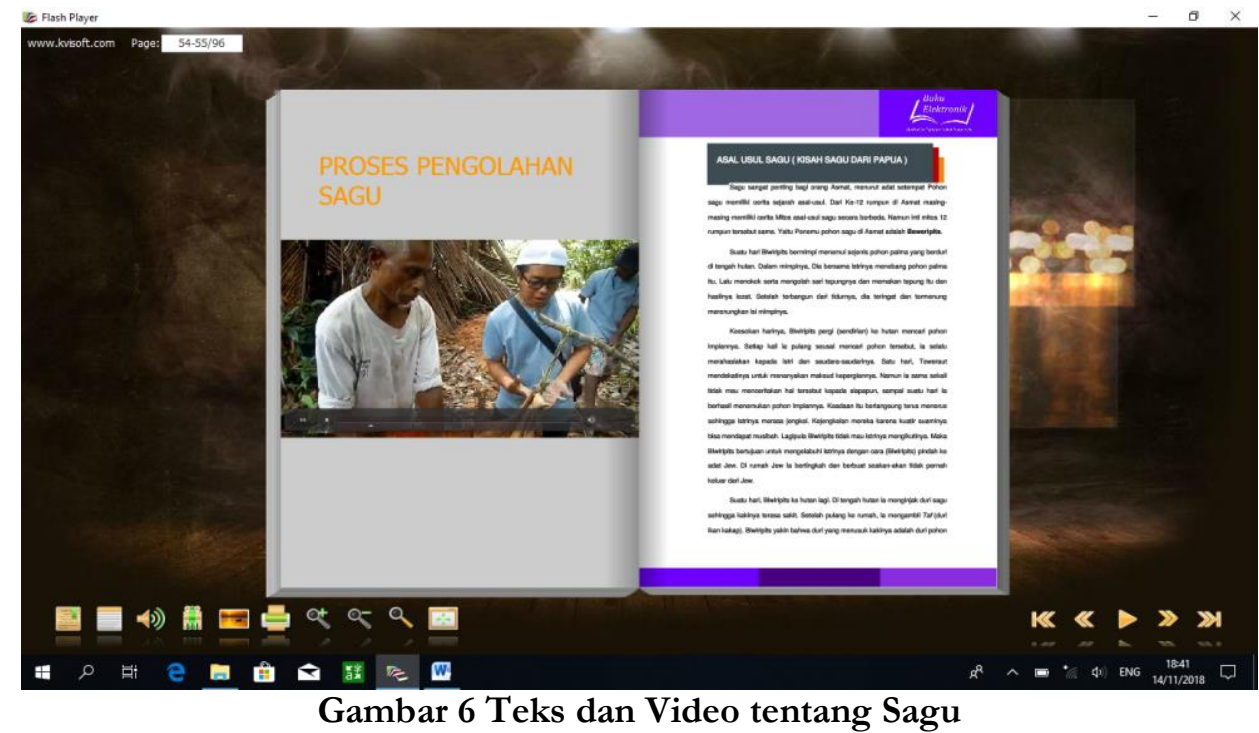

Aspek ketiga yang diformulasikan dalam buku pengayaan elektronik ini adalah grafika. Menurut Kamus Besar Bahasa Indonesia (KBBI, 2018) grafika adalah segala cara pengungkapan dan perwujudan dalam bentuk huruf, tanda, dan gambar yang diperbanyak melalui proses percetakan guna disampaikan pada khalayak. Unsur grafika yang ditampilkan dalam buku pengayaan elektronik ini berupa pemilihan huruf yang berkait (serif) dan huruf yang tidak berkait (sans serif). Serif adalah abjad yang mempunyai garis-garis kecil yang berdiri horizontal pada badan huruf (counterstroke) (desainstudio.com, 2010). Jenis abjad ini lebih mudah dibaca karena memandu 
pandangan pembaca melalui suatu garis teks. Abjad yang dikelompokkan sebagai kategori font serif adalah Times New Roman, Garamond, Book. Antiqua, Palatino Linotype, dan Bookman Old Style.

Sans serif adalah jenis abjad yang solid dan tidak mempunyai garis-garis kecil, fungsional, dan lebih terkesan modern (desainstudio.com, 2018). Jenis abjad yang termasuk Sans Serif adalah Century Gothic, Museo Sans, Avant Garde, dan Arial.Dalam buku pengayaan elektronik ini, dua jenis huruf Serif dan Sans Serif digunakan, dengan dua pertimbangan bahwa (1) dua jenis huruf ini lebih mudah dibaca dan (2) perjenjangan buku di tingkat $\mathrm{F}$ untuk membaca mahir merekomendasikan penggunaan salah satu dari dua jenis abjad itu. Buku ini menggunakan ukuran huruf 11, spasi satu, warna huruf hitam dan berwarna.

\section{PENUTUP}

Hasil studi pendahuluan atau analisis kebutuhan menunjukkan bahwa 100\% pembaca menyukai buku pengayaan elektronik. Buku pengayaan elektronik disukai pembaca karena menyediakan dan memenuhi kebutuhan pembaca terhadap teks nonfiksi dan fiksi, kalimat pemantik yang menjadi pengantar tiap bahasan bab, penggunaan bahasa formal dan nonformal, teks bacaan jenis trivia yang berisi informasi ringan seputar makanan pokok, dan aneka jenis teks dalam satu bab. Jenis huruf tertentu yang digunakan tidak menjadi pertimbangan utama pembaca, karena bagi mereka yang penting jenis huruf mudah terbaca. Fokus utama dari pembaca dari segi grafika adalah penggunaan warna dan desain grafik yang menarik sehingga membuat mereka mau membaca isi buku. Prosentase kesukaan dan kebutuhan responden terhadap isi menempati peringkat pertama, yaitu sebesar 55\%, diikuti oleh aspek kesukaan dan kebutuhan pada bahasa dan grafika sebesar $45 \%$. Pembaca menilai bahwa isi buku menempati posisi paling penting dalam buku pengayaan elektronik, disusul bahasa dan grafika.

Validasi ahli menunjukkan bahwa penilaian ahli materi terhadap kelayakan buku pengayaan elektronik adalah sebesar 84\%. Ahli media memberikan skor kelayakan buku 83\%, sedangkan ahli grafika menyatakan bahwa nilai kelayakan buku adalah 86\%. Hasil itu menunjukkan bahwa buku pengayaan elektronik ini layak digunakan sebagai buku bacaan untuk jenjang $\mathrm{F}$ (membaca mahir).

\section{DAFTAR PUSTAKA}

Ambarwati, A. (2019). Nusantara dalam Piringku. Jakarta: Gramedia Pustaka Utama.

Anisya, A \& Suyitno, I. (2018). Pengembangan E-book Memahami Cara Menulis Cerkak Bahasa Jawa dengan Menggunakan Ide Gambar Berseri untuk Siswa Kelas XII. BASINDO: Jurnal Kajian Bahasa, Sastra Indonesia, dan Pembelajarannya, 2 (1). Hal. 38-43. Dirujuk dari https://journal2.um.ac.id/ index.php/basindo/article/view/4155.

Buchory, MS, dkk. (2017). The Development of A Learning Media for Visualizing the Pancasila Values Based on Information and Communication Technology. Cakrawala Pendidikan: Jurnal Ilmiah Pendidikan, 36 (3), Hal. 502-521. Dirujuk dari https://journal.uny.ac.id/index.php/cp/article/view/12748.

Cardullo, V, dkk. (2017). Reading nonfiction text on an iPad in a secondary classroom. https://onlinelibrary.wiley.com/doi/epdf/10.1111/1467-9817.12099.

Desain Studio. (2010). Pengertian Serif dan Sans Serif. www.desainstudio.com/ search?q=sans + serif\&x $=0 \& y=0$. Diunduh 15 Maret 2018.

Dieda, E. (2016). 2016, 7 Juni. Indonesia Memiliki 77 Jenis Pangan Sumber Karbohidrat. Nusantara News, https://nusantaranews.co/indonesia-memiliki-77-jenis-pangan-sumberkarbohidrat/

Dirjendikdasmen Kemdikbud, (2016). Desain Induk Gerakan Literasi Sekolah.

Kamus Besar Bahasa Indonesia Daring. (2017). https://kbbi.kemdikbud.go.id/. Diunduh 29 Agustus 2018.

NN. (2018), 22 Februari. Keragaman Pangan Diabaikan. Kompas, https://kompas.id/baca/utama/2018/02/27/keragaman-pangan-diabaikan/ 
Oxford Dictionary Online. 2017. https://www.oxforddictionaries.com/. Diunduh 12 Juli 2018.

Permendiknas No 2 Tahun 2008. Permendiknas Tentang Buku. kelembagaan.ristekdikti.go.id/wp-content/uploads/2016/12/Isi-Permendiknas-2-thn2008.pdf. Diunduh 6 Februari 2016.

Puskurbuk. (2018). Naskah Akademik Perjenjangan Buku Nonteks Pelajaran. Badan Penelitian dan Pengembangan-Kementerian Pendidikan dan Kebudayaan RI.

Rahman, F. (2016). Jejak Rasa Nusantara: Sejarah Makanan Indonesia. Jakarta: Gramedia Pustaka Utama.

Shanahan, T., Fisher, D. \& Frey, N. (2012). The challenge of challenging text. Educational Leadership. journal of the Department of Supervision and Curriculum Development, 69 (6), hal. 58-62. Dirujuk dari www.ascd.org/publications/educationalleadership/mar12/vol69/num06/The-Challenge-of-Challenging-Text.aspx.

Wahyuni, S. (2012). Pengembangan Interactive E-Book Bidang Asesmen Bahasa Untuk Mengembangkan Kompetensi Dan Kemandirian Mahasiswa Program Pendidikan Bahasa. https://journal.uny.ac.id/index.php/litera/article/view/1908/1563 